\title{
Evaluation of dehydration mechanism during heating of hydrous asteroids based on mineralogical and chemical analysis of naturally and experimentally heated CM chondrites
}

\author{
Aiko Nakato ${ }^{1}$, Tomoki Nakamura ${ }^{1}$, Fumio Kitajima $^{1}$, and Takaaki Noguchi ${ }^{2}$ \\ ${ }^{1}$ Department of Earth and Planetary Sciences, Faculty of Sciences, Kyushu University, Hakozaki, Fukuoka 812-8581, Japan \\ ${ }^{2}$ College of Science, Ibaraki University, 2-1-1 Bunkyo, Mito 310-8512, Japan
}

(Received March 1, 2008; Revised May 16, 2008; Accepted May 17, 2008; Online published September 8, 2008)

\begin{abstract}
Based on the evidence derived from spectroscopic observation and meteorite analysis, some hydrous asteroids were heated and dehydrated for a certain period of time after aqueous alteration. In order to reproduce the dehydration processes, we experimentally heated Murchison $\mathrm{CM}$ chondrite at $600^{\circ} \mathrm{C}$ for $1 \mathrm{~h}\left(600^{\circ} \mathrm{C} / 1 \mathrm{~h}\right)$, $600^{\circ} \mathrm{C} / 96 \mathrm{~h}, 900^{\circ} \mathrm{C} / 1 \mathrm{~h}$, and $900^{\circ} \mathrm{C} / 96 \mathrm{~h}$ under controlled oxygen partial pressures. The experimental products were compared with Belgica (B-)7904 CM chondrite, a meteorite from a dehydrated asteroid in terms of characteristic mineralogical and compositional properties. B-7904 shows properties intermediate between the two experimental products heated at $900^{\circ} \mathrm{C} / 1 \mathrm{~h}$ and $900^{\circ} \mathrm{C} / 96 \mathrm{~h}$. In addition, the presence or the absence of some temperature-sensitive minerals in B-7904 suggests that it experienced heating at a temperature higher than $700^{\circ} \mathrm{C}$ but lower than $890^{\circ} \mathrm{C}$. The duration of heating, based on the diffusion time needed to achieve the Fe- $\mathrm{Mg}$ zoning profile in olivine in B-7904, was estimated to be between 10 and $10^{3}$ days at $700^{\circ} \mathrm{C}$ and between 1 to $10^{2} \mathrm{~h}$ at $890^{\circ} \mathrm{C}$. The obtained durations are much shorter than those expected from the internal heating model which requires prolonged heating over million years. Therefore, it is unlikely that the short-lived radionuclide of ${ }^{26} \mathrm{Al}$ is a heat source for the dehydration of B-7904. Instead, short-duration local heating, such as that from impacts or solar radiation, is a more promising heat source.
\end{abstract}

Key words: CM chondrites, dehydration, internal heating, heating experiments, Belgica7904.

\section{Introduction}

Telescopic observation suggests that many $\mathrm{C}$ type $(\mathrm{C}, \mathrm{G}$, $\mathrm{B}$, and $\mathrm{F}$ ) asteroids, similar to hydrous carbonaceous chrondites such as those of the CI and CM types, are composed mainly of hydrous minerals (Gaffy et al., 1989). This similarity suggests that extensive hydration reactions at low temperature, i.e., aqueous alteration, have taken place in C-type asteroids. However, a non-negligible number of C-type asteroids show reflectance spectra similar to those of thermally metamorphosed hydrous carbonaceous chondrites, suggesting that the dry surfaces of such C-type asteroids were the result of heating and dehydration (Hiroi et al., 1993, 1994, 1996; Hiroi and Zolensky, 1999).

More than 20 samples of hydrous carbonaceous chondrites, mostly CM chondrites, show evidence of dehydration due to high-temperature heating in parent asteroids (e.g., Ikeda, 1992). Many analyses have been carried out on such meteorites with the aim of gaining some understanding of the dehydration process from the viewpoint of mineralogy and petrology (Akai, 1988; Tomeoka et al., 1989a, b; Akai, 1990; Tomeoka, 1990a, b; Bischoff and Metzler, 1991; Ikeda, 1991), inorganic and organic chemistry (Kitajima et al., 2002; Yabuta et al., 2005), and noble gases (Nagao et al., 1984; Nakamura et al., 2006). The results have

Copyright (c) The Society of Geomagnetism and Earth, Planetary and Space Sciences (SGEPSS); The Seismological Society of Japan; The Volcanological Society of Japan; The Geodetic Society of Japan; The Japanese Society for Planetary Sciences; TERRAPUB led to the classification of heated hydrous chondrites into classes based on the degree of heating (Nakamura, 2005). In addition, several experimental studies attempted to reproduce mineralogical changes during dehydration: heating experiments (e.g., Miyamoto, 1991; Akai, 1992; Hiroi et al., 1993; Hiroi and Zolensky, 1999) and shock experiments (Tomeoka et al., 1999; Tomioka et al., 2007).

Despite the recent progress that has been made in characterizing dehydrated carbonaceous chondrites, several crucial issues remain to be clarified. Two of the areas of major controversy are the time period during which the hydrous asteroids were heated and the cause of the heating. In the study reported here, we evaluated both the temperature and the duration of heating that has taken place in hydrous asteroids based on mineralogical and chemical characteristics in naturally and experimentally heated CM chondrites, with an aim of setting constraints on the heat source for dehydration. To this end, detailed mineralogical and compositional properties of a dehydrated CM chondrite B-7904 were characterized by various analytical methods, and the obtained properties were experimentally reproduced by the heating of a hydrated CM chondrite, Murchison.

\section{Experimental Procedures \\ 2.1 Heating experiments}

Four sets of heating experiments were performed using a furnace (Fig. 1) and small pieces of Murchison under various conditions: $600^{\circ} \mathrm{C}$ for $1 \mathrm{~h}$ (hereafter $600^{\circ} \mathrm{C} / 1 \mathrm{~h}$ ), 


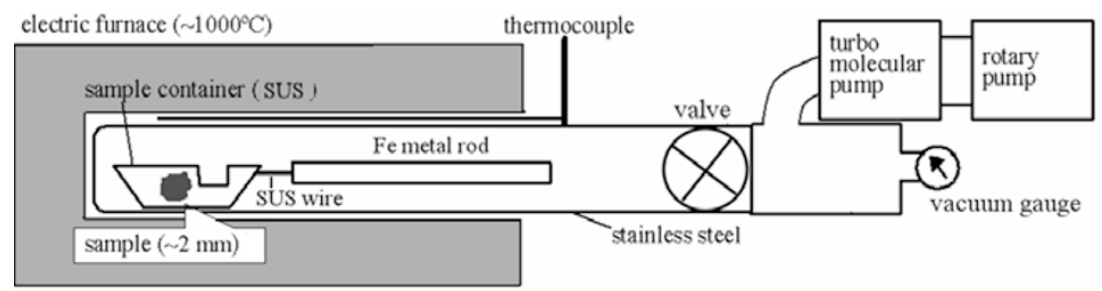

Fig. 1. An experimental set-up for heating a piece of Murchison CM chondrite. A small piece of Murchison CM chondrite, approximately 2 mm in diameter, was placed on a small sample container made of stainless steel. A Pt-Rh thermocouple was held right above the sample container but outside of the stainless steel tube. The tube was evacuated using a turbo-molecular pump down to $10^{-7}$ torr. The pressure was monitored using a BA vacuum gauge. A valve was closed during the heating to maintain constant oxygen partial pressure inside the tube.

$600^{\circ} \mathrm{C} / 96 \mathrm{~h}, 900^{\circ} \mathrm{C} / 1 \mathrm{~h}$, and $900^{\circ} \mathrm{C} / 96 \mathrm{~h}$. Two pieces of the Murchison sample particle, each approximately $2 \times 2 \times$ $0.5 \mathrm{~mm}$, were placed in a sample container and the container was set inside of a stainless tube (Fig. 1) that was evacuated down to approximately $1 \times 10^{-7}$ torr using a turbo-molecular pump. The stainless tube was then inserted into the furnace to heat the sample to a designated temperature. The pressure initially increased due to the degassing from the sample, the container, and the tube, but the pressure decreased within several minutes, and the valve between the sample and the pump was closed. The sample pieces were heated for 1 or $96 \mathrm{~h}$. During the heating period, the oxygen fugacity was kept at IW buffer by the hot Fe metal rod connecting to the sample container (Fig. 1), which is made of pure metallic iron; the other materials, such as the container and the tube, are made of stainless steel and therefore resistant to oxidation. We chose IW buffer in order to reproduce secondary iron-bearing minerals in B-7904 that contain both $\mathrm{Fe}$ and $\mathrm{Fe}^{2+}$. After heating, the container with samples was pulled out of the furnace for cooling, and the tube was opened to the air when it was cooled down to the room temperature.

\subsection{Observations of meteorite samples}

The polished slices of the unheated and the experimentally heated Murchison sample particles and that of the B-7904 were observed by a scanning electron microscope (SEM JEOL JSM-5800LV) and a field-emission scanning electron microscope (FE-SEM JEOL JSM-7000F), both of which were equipped with an energy dispersive spectrometer (EDS) to characterize textures and lithologies. The fine-scale $\mathrm{Fe} /(\mathrm{Mg}+\mathrm{Fe})$ distribution in olivine in chondrules and that in fine-grained matrix was determined with the FE-SEM/EDS using a thin electron beam with an analyzed area approximately $0.4 \mu \mathrm{m}$ across. The major element concentrations of the rims around the chondrules were determined with an electron probe micro-analyzer equipped with a wave-length dispersive spectrometer (EPMA/WDS JEOL JXA-733 superprobe) using an electron beam $20 \mu \mathrm{m}$ in diameter.

The areas of interest, approximately $100 \mu \mathrm{m}$ in diameter, were then removed from the sample using the edged tools and subsequently exposed to synchrotron X-rays with a wave length of $2.161 \pm 0.001 \AA$ using the Gandolfi camera to produce X-ray diffraction (XRD) patterns (Nakamura et al., 2008). The XRD analysis was performed at beam line 9C of the Photon Factory Institute of Material Science, High Energy Accelerator Research Organization. The ultrahigh intensity and perfectly monochromated X-rays allowed us to obtain a clear XRD pattern from individual small samples with a short exposure of approximately $30 \mathrm{~min}$. The Raman spectra were obtained using NRS-3000 Raman spectrometer. An excitation wavelength of $785 \mathrm{~nm}$ was used on an $\mathrm{Ar}^{+}$laser. The laser beam was focused using a microscope equipped with a $100 \times$ objective, leading to a spot diameter of several microns. The power at the sample surface was $0.7 \mathrm{~mW}$. The spectra were interpreted based on the model proposed by Beyssac et al. (2002). However, as the so-called $\mathrm{D}_{2}$-band, which may appear as a shoulder at the higher wave-number side of the G-band, was not observed in this case, we used the $\mathrm{D}_{1^{-}}, \mathrm{D}_{3^{-}}$, and G-components.

\section{Results}

Detailed mineralogical and chemical characterization was carried out, and the observed differences between B-7904 and the unheated Murchison and the progressive changes during experimental heating of Murchison are described below.

\subsection{Texture}

The unheated Murchison (Fig. 2(a)) shows overall textures of typical $\mathrm{CM}$ chondrites: the chondrules, typically $300-500 \mu \mathrm{m}$ in diameter, are embedded in finegrained matrix materials. Most of the chondrules are surrounded by fine-grained dust rims that are approximately $100 \mu \mathrm{m}$ in thickness (Fig. 2(a)). The rims consist mainly of fine-grained hydrous silicate serpentine $(\mathrm{Mg}$, $\mathrm{Fe})_{6} \mathrm{Si}_{4} \mathrm{O}_{10}(\mathrm{OH})_{6}$. Fe-, Si-, and $\mathrm{S}$-rich objects, typically 20-100 $\mu \mathrm{m}$ in size, ubiquitously occur outside the rims (Fig. 2(b)); these are PCPs (poorly characterized phases: Fuchs et al., 1973), known as mixed phases of tochilinite $6 \mathrm{Fe}_{0.9} \mathrm{~S} \cdot 5(\mathrm{Mg}, \mathrm{Fe})(\mathrm{OH})_{2}$ and Fe-rich serpentine cronstedtite $\left(\mathrm{Mg}, \mathrm{Fe}^{2+}\right)_{6}\left(\mathrm{Si}, \mathrm{Fe}^{3+}\right)_{4} \mathrm{O}_{10}(\mathrm{OH})_{6}$ (Tomeoka and Buseck, 1983; MacKinnon and Zolensky, 1984; Tomeoka and Buseck, 1985; Nakamura and Nakamuta, 1996). The PCPs are also surrounded by fine-grained thin rims similar in mineralogy to those around the chondrules (Metzler et al., 1992).

Experimental heating of Murchison did not change the overall textures significantly. The textures of the experimental product of the Murchison heated at $900^{\circ} \mathrm{C} / 96 \mathrm{~h}$ are shown in Figs. 2(c) and 2(d). Some cracks are generated perpendicular to the surfaces of the chondrule. These likely formed during dehydration because they are not observed in unheated Murchison and, in addition, dehydration causes shrinkage in hydrous materials. Marked textural changes 

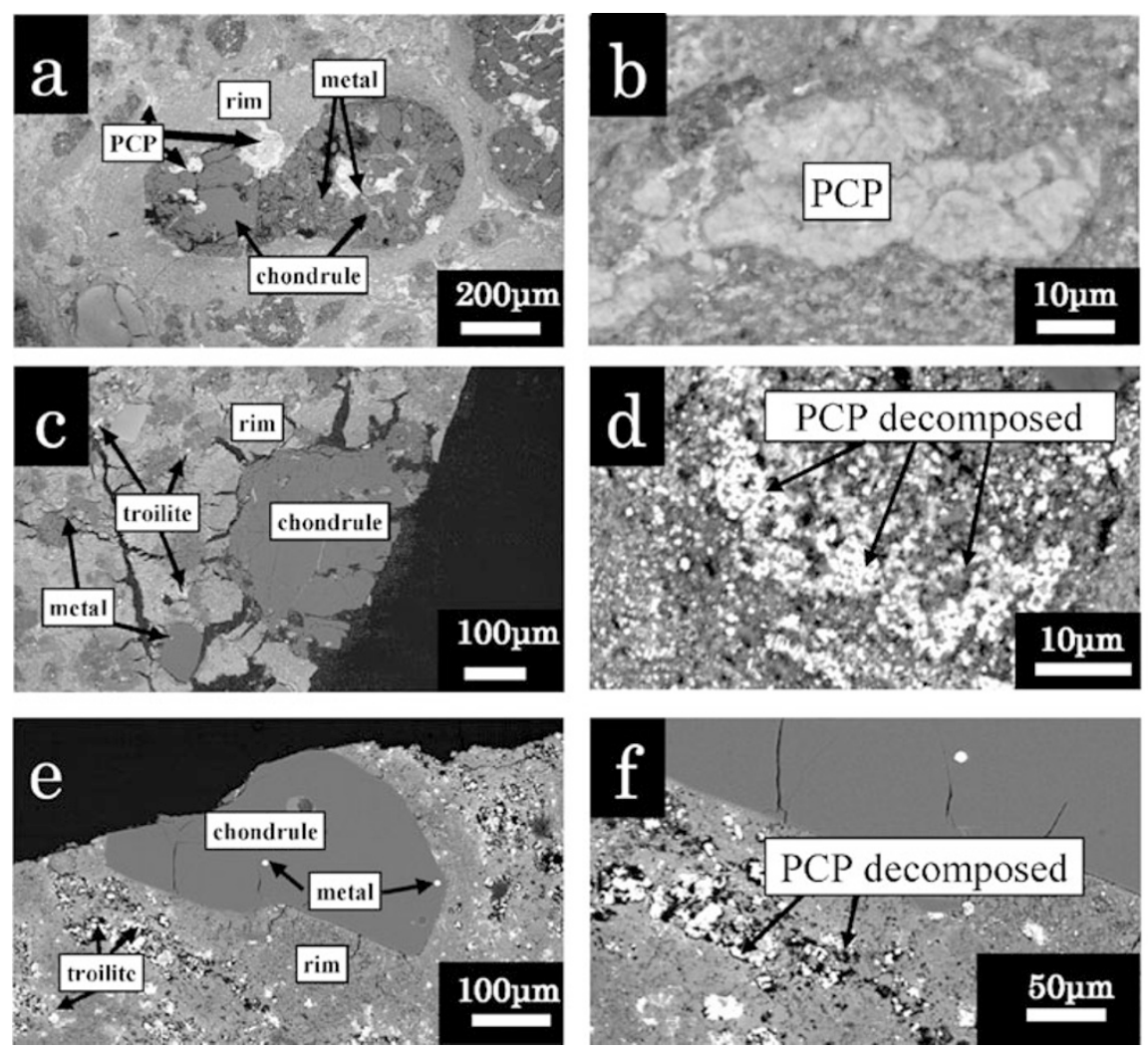

Fig. 2. Back-scattered electron (BSE) images of parts of polished slices. (a) Unheated Murchison consisting of chondrules, fine-grained rims, and PCPs around the chondrules. (b) An enlarged view of the unheated Murchison; PCPs (bright objects) are present outside a rim. (c) Experimental product of Murchison heated at $900^{\circ} \mathrm{C} / 96 \mathrm{~h}$, consisting of chondrules and rims; small troilite particles are abundant instead of PCPs. (d) An enlarged view of the Murchison heated at $900^{\circ} \mathrm{C} / 96 \mathrm{~h}$. PCPs in the matrix are decomposed to troilite, Fe metal, and anhydrous silicates. (e) B-7904. Like Murchison, it consists of chondrules and their rims, but unlike the unheated Murchison, PCPs are decomposed, similar to the heated Murchison in (d). (f) An enlarged view of B-7904. Porous aggregates of troilite, metal, and silicates commonly occur both in the rims around chondrules and in the matrix; these are decomposed PCPs.
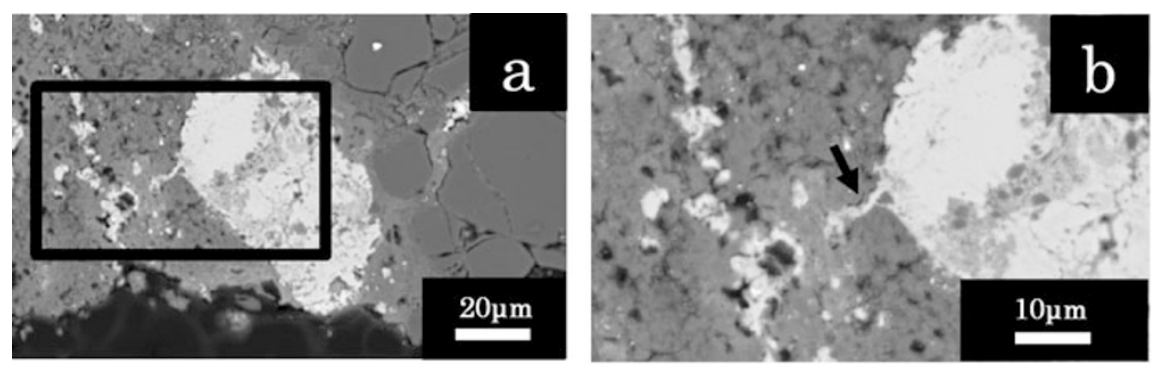

Fig. 3. BSE images of B-7904. (a) A large troilite grain on the surface of a chondrule (right part of the image). (b) High magnification view of the region outlined by a rectangle in (a). A melted vein is indicated by an arrow.

occurred in the PCPs. Small troilite, kamacite, taenite, and olivine grains less than $0.1 \mu \mathrm{m}$ formed at the expense of tochilinite and cronstedtite, which changes the overall textures of PCPs from a smooth and massive appearance (Fig. 2(b)) to a porous and lumpy one (Fig. 2(d)). Fe-Mg zoning developed at the edge of the Mg-rich olivine crystals in chondrules because the $\mathrm{Fe} / \mathrm{Mg}$ ratios of the rims enclosing chondrules are much higher than those of the chondrules themselves. The width of the zoned area is too narrow to observe with normal BSE imaging. Therefore, high-resolution imaging using FE-SEM was performed, and the results are given in Section 3.4.

In addition to phyllosilicates, CM chondrites contain several minerals that are decomposed at relatively low temper- atures which, therefore, can be used as temperature indicators. Pentlandite, with a decomposition temperature of $610^{\circ} \mathrm{C}$ (Etschmann et al., 2004), commonly occurs in the fine-grained matrix of Murchison. It survives experimental heating at $600^{\circ} \mathrm{C} / 1 \mathrm{~h}$ and $600^{\circ} \mathrm{C} / 96 \mathrm{~h}$, but decomposes to troilite + taenite assemblages with heating at $900^{\circ} \mathrm{C} / 1 \mathrm{~h}$ and $900^{\circ} \mathrm{C} / 96 \mathrm{~h}$. In the same way, calcite, decomposes at $890^{\circ} \mathrm{C}$ (Deer et al., 1992), survives heating at $600^{\circ} \mathrm{C}$, but breaks down at $900^{\circ} \mathrm{C}$.

The CM chondrite B-7904, heated in space, shows textures basically similar to those of the unheated Murchison in terms of the thickness of the rims and the size and the abundance of chondrules (Fig. 2(e)). However, it is more similar to the experimental products heated at $900^{\circ} \mathrm{C} / 1 \mathrm{~h}$ 

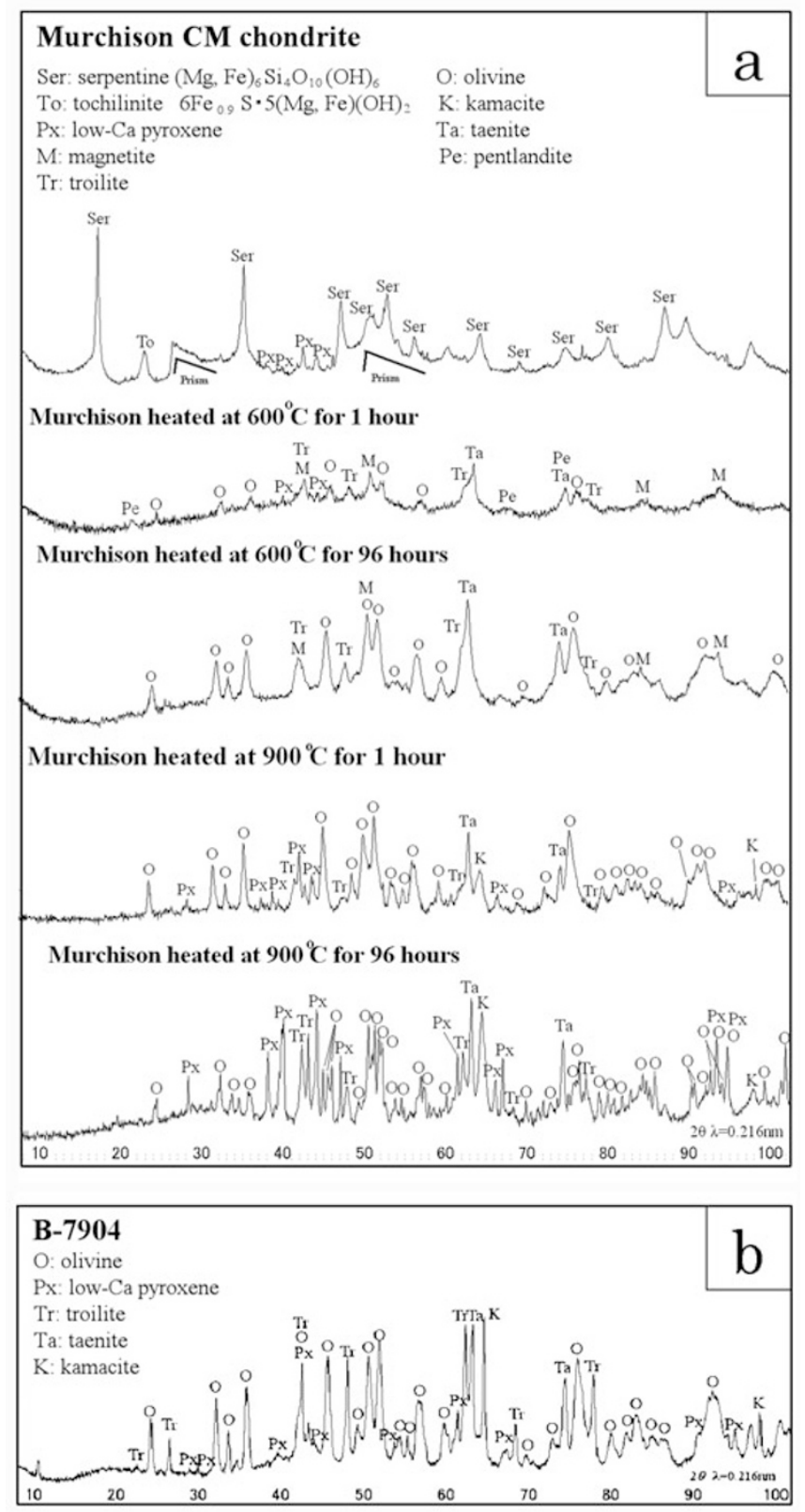

Fig. 4. Synchrotron X-ray diffraction patterns of matrices in carbonaceous chondrites and experimental products. (a) Murchison and experimental products showing changes in bulk mineralogy during heating. Decomposition of many primary phases in Murchison, such as serpentine and tochilinite, and recrystallization of secondary-phases, such as olivine and pyroxene, occurred with increasing temperature and duration time. (b) B-7904 showing that constituent minerals are similar to those of the products of Murchison heated at $900^{\circ} \mathrm{C}$. B-7904 does not preserve primary hydrous phases.

and $900^{\circ} \mathrm{C} / 96 \mathrm{~h}$ (Fig. 2(d)) because both B-7904 and the two products contain abundant decomposed PCPs and no pentlandite crystals (Fig. 2(f)). Our survey fails to detect calcite in B-7904, but its presence in the meteorite was reported in a previous study (Kimura and Ikeda, 1992). Large $\mathrm{Fe}-\mathrm{FeS}$ objects on the surface of a chondrule show a trace of melting (Fig. 3(a)): small Fe-S-Ni melt veins are generated from the object into a fine-grained matrix (Fig. 3(b)). This melting indicates that the objects were heated at temperature above the $\mathrm{Fe}-\mathrm{FeS}$ eutectic melting point, $988^{\circ} \mathrm{C}$. However, small troilite blebs in the decomposed PCPs do not show any evidence of melting, suggesting a heterogeneous temperature distribution during heating.

\subsection{Mineral combination}

Experimental heating drastically changes the mineralogy of phyllosilicates in Murchison, and the changes with increasing temperatures and heating durations can be clearly traced in the XRD patterns of the matrices (Fig. 4(a)). Serpentine and tochilinite are major hydrous phases in the unheated matrix of Murchison. At $600^{\circ} \mathrm{C}$, both of these phases are decomposed and secondary olivine, troilite, and taenite are formed (Fig. 4(a)). The reflections of the three secondary phases are much sharper and higher in the $600^{\circ} \mathrm{C} / 96 \mathrm{~h}$ product than in the $600^{\circ} \mathrm{C} / 1 \mathrm{~h}$ product, suggesting that recrystallization proceeds with time. At $600^{\circ} \mathrm{C}$, serpentine is decomposed but not completely dehydrated, allowing for the presence of magnetite even after $96 \mathrm{~h}$ of 

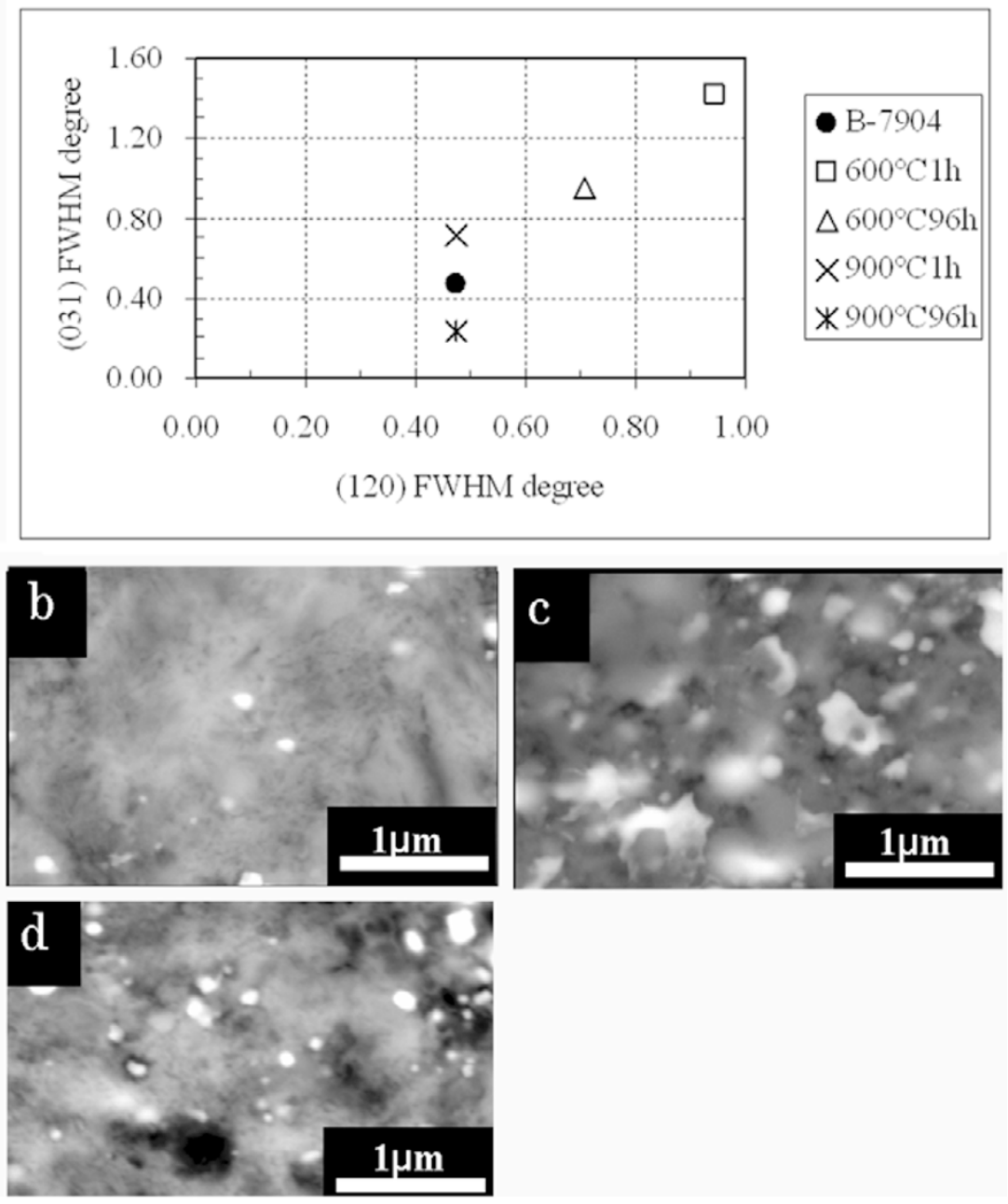

Fig. 5. A diagram and high-resolution images showing the crystallization degrees of the secondary olivine in matrices of B-7904 and experimental products. (a) FWHM (Full Width at Half Maximum) of (120) and (031) reflections from the secondary olivine, determined from X-ray diffraction patterns (Fig. 4), decreases with increasing temperature and duration time. (b) A BSE image of fine-grained matrix in Murchison showing the characteristic fibrous texture of phyllosilicates. (c) A BSE image of the matrix in the product heated at $900^{\circ} \mathrm{C} / 96 \mathrm{~h}$ showing that fibrous phyllosilicates were decomposed and secondary olivine (dark grains in the figure), approximately 100-300 nm in size, formed during heating. (d) A BSE image of the matrix in B-7904 showing an intermediate texture between (b) and (c).

heating. On the other hand, at $900^{\circ} \mathrm{C}$, dehydration is complete and, therefore, magnetite has disappeared and secondary kamacite and taenite have formed. In addition to olivine, secondary low-Ca pyroxene forms at $900^{\circ} \mathrm{C} / 1 \mathrm{~h}$ and further crystallizes at $900^{\circ} \mathrm{C} / 96 \mathrm{~h}$. All reflections from the $900^{\circ} \mathrm{C} / 96 \mathrm{~h}$ product are very sharp, reflecting the high degrees of crystallization of the secondary phases, including olivine, pyroxene, troilite, kamacite, and taenite.

The XRD pattern of B-7904 shows that no phyllosilicates are present in fine-grained matrix (Fig. 4(b)). Crystalline olivine, troilite, kamacite, and taenite are major phases, and small amounts of low-Ca pyroxene are also detected. The combination and the crystallinity of minerals in B-7904 are more similar to the product of $900^{\circ} \mathrm{C} / 1 \mathrm{~h}$ (Fig. 4) than to the product of $900^{\circ} \mathrm{C} / 96 \mathrm{~h}$ because only the $900^{\circ} \mathrm{C} / 96 \mathrm{~h}$ product contains abundant pyroxene (Fig. 4).

\subsection{Crystallinity of secondary olivine}

As shown in the XRD patterns of the experimentally heated Murchison (Fig. 4(a)), the degree of recrystallization of the secondary olivine depends on both the time and the temperature of heating. The reflections from olivine become higher and narrower with increasing crystallinity. Full width at half maxima (FWHM) of (031) and (120) reflections of olivine were obtained by the profile fitting method in order to quantify the recrystallization degrees (Fig. 5(a)). The FWHM of both reflections decreases with increasing time and temperature of heating. The FWHM of $900^{\circ} \mathrm{C} / 1 \mathrm{~h}$ is smaller than that of $600^{\circ} \mathrm{C} / 96 \mathrm{~h}$, indicating that temperature is more effective than time for recrystallization. Heating at $900^{\circ} \mathrm{C} / 96 \mathrm{~h}$ changes the micro-texture of matrix significantly from the fibrous, massive morphology of the unheated Murchison (Fig. 5(b)) to the porous aggregates of discrete grains (Fig. 5(c)). The product of the $900^{\circ} \mathrm{C} / 96 \mathrm{~h}$ treatment shows the smallest FWHM and contains secondary olivine with grains typically varying in size from 100 to $300 \mathrm{~nm}$ (Fig. 5(c)). B-7904 shows a FWHM that is intermediate between those of the $900^{\circ} \mathrm{C} / 1 \mathrm{~h}$ and $900^{\circ} \mathrm{C} / 96 \mathrm{~h}$ products. The matrix of B-7904 contains discrete grains of secondary olivine (Fig. 5(d)), but portions remain with a fibrous texture, suggesting that the crystallinity is lower than that of the $900^{\circ} \mathrm{C} / 96 \mathrm{~h}$ product (Fig. 5(c)). 

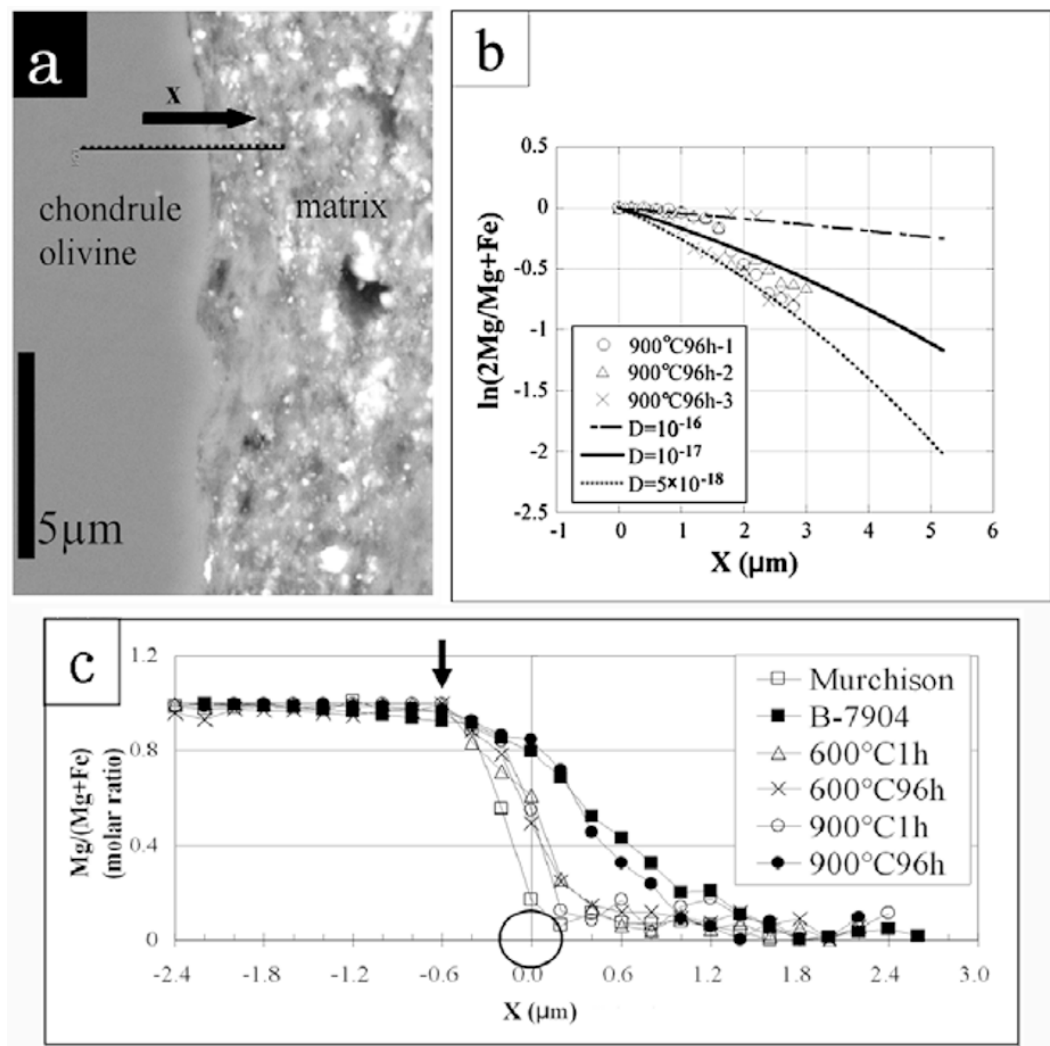

Fig. 6. Fe-Mg diffusion in chondrule olivines of Murchison, B-7904 and experimental products. (a) A BES image of B-7904. Very narrow Fe-Mg zoning was observed at most outer portions of a chondrule olivine, suggesting that Fe-Mg diffusion occurred, but only over short distance in B-7904. A sequential line analysis was performed across the zoned area, and the line and the analyzed points are shown. X in (a) corresponds to the horizontal axis in (c). (b) Fe-Mg diffusion profiles taken from three different olivines in the product heated at $900^{\circ} \mathrm{C} / 96 \mathrm{~h}$. The calculated profiles with three different diffusion coefficients $\left(5 \times 10^{-18}<D<1 \times 10^{-16} \mathrm{~m}^{2} / \mathrm{s}\right)$ are also shown for comparison. Origin in the $\mathrm{X}$ axis corresponds to the position of the onset of diffusion, and position is indicated by an arrow in (c). (c) Fe-Mg diffusion profiles of unheated and heated Murchison and B-7904. The profile of B-7904 is very similar to that of the $900^{\circ} \mathrm{C} / 96 \mathrm{~h}$ product. A circle in (c) represents the electron beam size used in the FE-SEM analysis.

\subsection{Fe-Mg zoning of primary olivine}

During the heating treatments, Fe-Mg inter-diffusion occurred between $\mathrm{Mg}$-rich chondrule olivine and Fe-rich matrix material, as is commonly observed in thermally metamorphosed ordinary chondrites. Olivine grains at the peripheries of the chondrules in B-7904 ubiquitously show narrow Fe-Mg compositional zoning (Fig. 6(a)). The $\mathrm{Mg} /(\mathrm{Mg}+\mathrm{Fe})$ profiles of the zoning were measured at $0.2-$ $\mu \mathrm{m}$ intervals using a thin electron beam of FE-SEM, and the results are shown in Fig. 6(c) together with the profiles of the experimental products. The product heated at $900^{\circ} \mathrm{C} / 96 \mathrm{~h}$ best reproduces the zoning profile of $\mathrm{B}$ 7904 (Fig. 6(c)). Three profiles were obtained from the $900^{\circ} \mathrm{C} / 96 \mathrm{~h}$ product (Fig. 6(b)) to estimate the Fe-Mg diffusion constant of the chondrule olivine at $900^{\circ} \mathrm{C}$. The obtained constants range from $5 \times 10^{-18}$ to $1 \times 10^{-16} \mathrm{~m}^{2} / \mathrm{s}$ (Fig. 6(b)), with the best estimate being $1 \times 10^{-17} \mathrm{~m}^{2} / \mathrm{s}$. This value is close to that reported in a previous experimental study $\left(2 \times 10^{-17} \mathrm{~m}^{2} / \mathrm{s}\right.$ for Fo86 at $900^{\circ} \mathrm{C}$; Misener, 1974).

\subsection{Chemical composition}

Heating causes the dehydration of serpentine and tochilinite (Fig. 4(a)). The degree of dehydration is measured by an increase in total values in electron-probe measurements because EPMA can not detect light elements (e.g., H, O). Rims around chondrules consist mainly of serpentine and are therefore subject to dehydration during heating. Broad- electron beam analysis of the rims showed that the totals increase with increasing heating time and temperature (Table 1; Fig. 7). Dehydration is incomplete at $600^{\circ} \mathrm{C} / 1 \mathrm{~h}$ but almost complete at $600^{\circ} \mathrm{C} / 96 \mathrm{~h}(93 \mathrm{wt} \%$ total $)$. It completes at $900^{\circ} \mathrm{C} / 1 \mathrm{~h}(93 \mathrm{wt} \%$ total $)$, and no further increase is observed at $900^{\circ} \mathrm{C} / 96 \mathrm{~h}$ (Table 1). An approximately $7 \mathrm{wt} \%$ difference to $100 \mathrm{wt} \%$ remains, even in the total of $900^{\circ} \mathrm{C} / 96 \mathrm{~h}$ (93 wt \% total). This difference is likely due to (1) the presence of carbonaceous materials, whose abundance is of the order of several percent in Murchison (Jarosewich, 1990), and (2) the roughness of polished sample surfaces, which causes a reduction in the totals by several percent. In contrast, , B-7904 is well dehydrated, and its total is comparable to that of the $600^{\circ} \mathrm{C} / 96 \mathrm{~h}, 900^{\circ} \mathrm{C} / 1 \mathrm{~h}$, and $900^{\circ} \mathrm{C} / 96 \mathrm{~h}$ products (Table 1; Fig. 7). Sulfur is the most volatile element among the 13 elements analyzed, but it does not show any significant depletion in both any experimental product and B-7904 (Table 1), indicating that heating does not change compositions of major elements.

\subsection{Thermal evolution of amorphous carbonaceous} material

Maturity levels of carbonaceous materials can be determined by the deconvolution of the Raman spectra and the observed spectra interpreted based on the four-components model proposed by Beyssac et al. (2002). An ideal graphite crystal has only the G-band that corresponds to an ideal 
Table 1. Electron microprobe analyses of rims around chondrules in B-7904, Murchison, and experimental products (wt\%).

\begin{tabular}{|c|c|c|c|c|c|c|}
\hline $\mathrm{wt} \%$ & Murchison & $600^{\circ} \mathrm{C} / 1 \mathrm{~h}$ & $600^{\circ} \mathrm{C} / 96 \mathrm{~h}$ & $900^{\circ} \mathrm{C} / 1 \mathrm{~h}$ & $900^{\circ} \mathrm{C} / 96 \mathrm{~h}$ & B-7904 \\
\hline $\mathrm{SiO}_{2}$ & 25.2 & 27.4 & 29.7 & 27.4 & 30.4 & 34.8 \\
\hline $\mathrm{TiO}_{2}$ & 0.1 & 0.1 & 0.1 & 0.1 & 0.1 & 0.2 \\
\hline $\mathrm{Al}_{2} \mathrm{O}_{3}$ & 3.5 & 3.1 & 2.8 & 3.1 & 3.5 & 3.0 \\
\hline $\mathrm{FeO}$ & 28.0 & 31.3 & 28.0 & 35.1 & 33.8 & 18.6 \\
\hline $\mathrm{MnO}$ & 0.2 & 0.3 & 0.3 & 0.3 & 0.4 & 0.3 \\
\hline $\mathrm{MgO}$ & 14.5 & 16.2 & 17.6 & 16.2 & 17.6 & 22.0 \\
\hline $\mathrm{CaO}$ & 1.0 & 0.9 & 1.3 & 1.0 & 1.1 & 1.3 \\
\hline $\mathrm{Na}_{2} \mathrm{O}$ & 0.2 & 0.2 & 0.3 & 0.2 & n.d. & 0.9 \\
\hline $\mathrm{K}_{2} \mathrm{O}$ & n.d. & n.d. & 0.1 & 0.1 & 0.1 & 0.2 \\
\hline $\mathrm{Cr}_{2} \mathrm{O}_{3}$ & 0.4 & 0.4 & 0.5 & 0.4 & 0.4 & 0.5 \\
\hline $\mathrm{NiO}$ & 1.0 & 1.0 & 2.2 & 1.9 & 0.7 & 0.8 \\
\hline $\mathrm{P}_{2} \mathrm{O}_{5}$ & 0.2 & 0.2 & 0.3 & 0.3 & 0.3 & 0.2 \\
\hline $\mathrm{FeS}$ & 6.1 & 6.5 & 9.9 & 8.2 & 4.2 & 9.0 \\
\hline Total & 80.7 & 87.4 & 93.1 & 93.1 & 92.6 & 91.1 \\
\hline Number of analysis & 33 & 27 & 27 & 23 & 27 & 25 \\
\hline Standard deviations & 2.1 & 2.8 & 2.0 & 3.0 & 2.7 & 2.7 \\
\hline
\end{tabular}

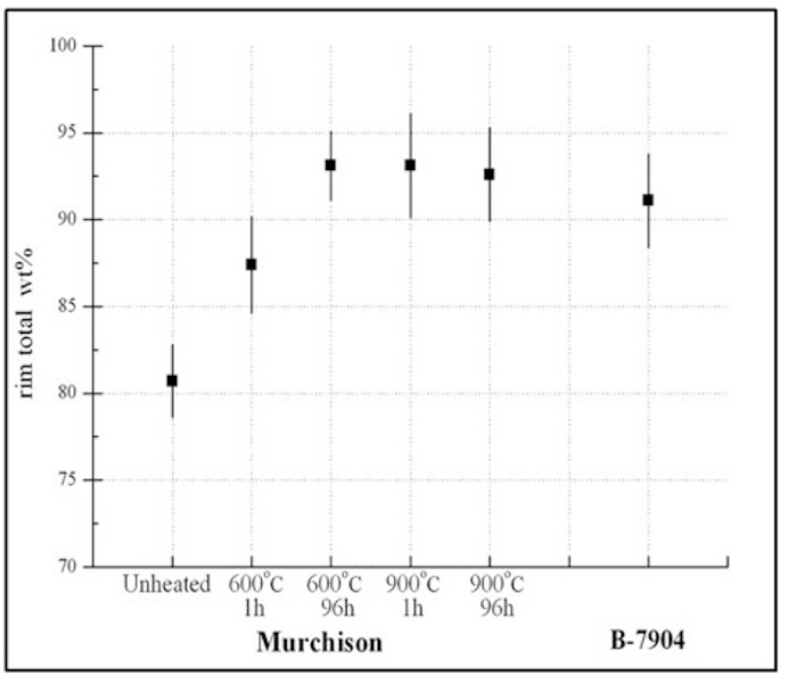

Fig. 7. A diagram showing average values (points) and standard deviations (bars) of total values of quantitative major element concentrations in rims around chondrules. Unheated Murchison has the lowest value because it retains phyllosilicates. However, experimentally heated Murchison and B-7904 have totals higher than the unheated Murchison due to decomposition and dehydration of phyllosilicates.

graphitic lattice vibration mode with $\mathrm{E}_{2 \mathrm{~g}}$ symmetry (Tuinstra and Koenig, 1970). The D-bands decrease in intensity relative to the G-band, with increasing maturity levels corresponding to the development of graphite crystallite. In more detail, the D-band consists of three components. The $\mathrm{D}_{2}$-component was not observed in such samples of lower maturity level as those in this study. Other components are as follows:

- $\mathrm{D}_{1}$ : The most intense D-band, corresponding to a disordered graphic lattice vibration mode with $\mathrm{A}_{1 \mathrm{~g}}$ symmetry. This vibration mode has been suggested to arise from graphene layer carbon atoms in the immediate vicinity of a lattice disturbance, such as the edge of a graphene layer (Katagiri et al., 1988), or a heteroatom
(Wang et al., 1989).

- $\mathrm{D}_{3}$ : Assigned to amorphous carbon fraction of organic molecule, fragments or functional groups (Cuesta et al., 1994; Jawhari et al., 1995).

All spectra of Murchison, B-7904, and the experimental products show the $\mathrm{D}_{1^{-}}, \mathrm{D}_{3-}$, and G-bands at $\sim 1350, \sim 1550$, and $1600 \mathrm{~cm}^{-1}$, respectively, and these spectra were fitted with a Pseudo-Voigt (PsVoigt) function. With respect to the maturity level in this study, the intensity of the $\mathrm{D}_{1}$-band relative to that of the G-band decreases with an increase of maturity, and FWHM-D ${ }_{1}$ also decreases. Figure 5 therefore indicates the following maturation grade of the carbonaceous materials in the experimental products and B-7904: $600^{\circ} \mathrm{C} / 1 \mathrm{~h}<600^{\circ} \mathrm{C} / 96 \mathrm{~h}<900^{\circ} \mathrm{C} / 1 \mathrm{~h}=900^{\circ} \mathrm{C} / 96 \mathrm{~h}=\mathrm{B}-$ 7904.

\section{Discussion}

\subsection{Constraint on the time and the temperature of heating experienced by B-7904}

Similarities between B-7904 and the experimentally heated Murchison are summarized in Table 2. Experimental heating at $600^{\circ} \mathrm{C}$ failed to reproduce many of the features of B-7904, whereas the heating at $900^{\circ} \mathrm{C}$ reproduced most of the mineralogical and chemical properties. The dehydration degree derived from the electron-probe analysis (Fig. 7) and the graphitization degree from the Raman analysis (Fig. 8) cannot be applied for the time and the temperature estimation for B-7904 because these two reactions are almost complete when heated for $1 \mathrm{~h}$ at $900^{\circ} \mathrm{C}$. In contrast, the crystallization degree of the secondary silicates (Figs. 4 , 5(a)) and the $\mathrm{Fe}-\mathrm{Mg}$ diffusion profiles in primary olivine (Fig. 6(c)) differ between the $900^{\circ} \mathrm{C} / 1 \mathrm{~h}$ and $900^{\circ} \mathrm{C} / 96 \mathrm{~h}$ treatments and thus can be used to constrain the conditions of heating. As the crystallization degree of secondary olivine in B-7904 is lower than that of $900^{\circ} \mathrm{C} / 96 \mathrm{~h}$ product (Fig. 5(a)), the time of heating will be shorter than $96 \mathrm{~h}$, assuming that B-7904 is heated at $900^{\circ} \mathrm{C}$. In contrast, the $\mathrm{Fe}-\mathrm{Mg}$ zoning in olivine in B-7904 is wider than that in the 
Table 2. Summary of the comparison between B-7904 and the experimental products of Murchison.

\begin{tabular}{|c|c|c|c|c|}
\hline & \multicolumn{4}{|c|}{ Heating experiment products } \\
\hline & $600^{\circ} \mathrm{C} / 1 \mathrm{~h}$ & $600^{\circ} \mathrm{C} / 96 \mathrm{~h}$ & $900^{\circ} \mathrm{C} / 1 \mathrm{~h}$ & $900^{\circ} \mathrm{C} / 96 \mathrm{~h}$ \\
\hline Inter-diffusion of $\mathrm{Fe}-\mathrm{Mg}$ in primary olivine & $\mathrm{X}$ & $\mathrm{X}$ & $\mathrm{X}$ & $\mathrm{O}$ \\
\hline Dehydration of the phyllosilicates & $\mathrm{X}$ & $\mathrm{O}$ & $\mathrm{O}$ & $\mathrm{O}$ \\
\hline Crystallinity of secondary olivine & $\mathrm{X}$ & $\mathrm{X}$ & $\triangle$ & $\triangle$ \\
\hline Crystallinity of amorphous carbonaceous materials & $\mathrm{X}$ & $\mathrm{X}$ & $\mathrm{O}$ & $\mathrm{O}$ \\
\hline Combination of minerals & $\mathrm{X}$ & $\mathrm{X}$ & $\mathrm{O}$ & $\mathrm{O}$ \\
\hline
\end{tabular}

"O" indicates that the product fully reproduces the properties of B-7904; " $\triangle$ " indicates partial reproduction of the B-7904 properties; "X" indicates no reproduction of the B-7904 properties.

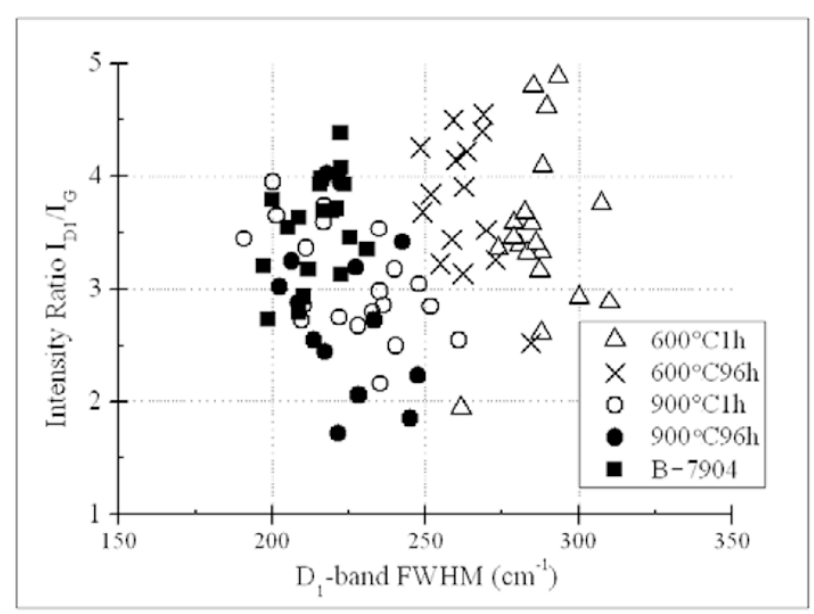

Fig. 8. A diagram showing the thermal evolution of carbonaceous materials in experimental products and B-7904. With increasing temperature, FWHM of $\mathrm{D}_{1}$-band decreases.

product of $900^{\circ} \mathrm{C} / 1 \mathrm{~h}($ Fig. $6(\mathrm{c}))$, suggesting that at $900^{\circ} \mathrm{C}$ the time of heating is longer than $1 \mathrm{~h}$. Therefore, at $900^{\circ} \mathrm{C}$, the heating time between $1 \mathrm{~h}$ and $96 \mathrm{~h}$ is appropriate to reproduce the mineralogical and compositional properties of B-7904. To constrain yet further, we need to determine the temperature of heating. For this purpose, some minerals are useful as temperature indicators. Pentlandite decomposes at $610^{\circ} \mathrm{C}$ (Etschmann et al., 2004). In B-7904, pentlandite is absent, but its decomposed assemblage (troilite + taenite) is present, suggesting that the temperature of heating exceeds $610^{\circ} \mathrm{C}$. In addition, the formation of the secondary pyroxene from decomposed phyllosilicates requires temperatures higher than $700^{\circ} \mathrm{C}$ based on the long-duration heating experiments reported by Akai (1992). Therefore, the presence of the secondary pyroxene in B-7904 indicates that the heating temperature is higher than $700^{\circ} \mathrm{C}$. On the other hand, calcite survives in B-7904 (Kimura and Ikeda, 1992), suggesting that the heating temperature is lower than $890^{\circ} \mathrm{C}$, the calcite decomposition temperature (Deer et al., 1992). In summary, the presence of the secondary low-Ca pyroxene and calcite and the absence of pentlandite in $\mathrm{B}$ 7904 suggest that the heating temperature is intermediate between 700 and $890^{\circ} \mathrm{C}$.

The approximate time of heating at $890^{\circ} \mathrm{C}$ ranges from 1 to $10^{2} \mathrm{~h}$, because again the time at $900^{\circ} \mathrm{C}$ ranges from 1 to $96 \mathrm{~h}$. The time of heating at $700^{\circ} \mathrm{C}$ is calculated from the time needed to produce the Fe-Mg zoning in B-7904. The Fe-Mg diffusion constant for olivine at $700^{\circ} \mathrm{C}$ is ob- tained using the activation energy given in Misener (1974) and the diffusion constant at $900^{\circ} \mathrm{C}\left(1 \times 10^{-17} \mathrm{~m}^{2} / \mathrm{s}\right)$ estimated in this study. The results of calculation show that, at $700^{\circ} \mathrm{C}$, the heating time is intermediate between 10 and $10^{3}$ days. Therefore, based on all of the evidence taken together, the heating conditions for B-7904 can be estimated to be between $1 \mathrm{~h}$ and $10^{3}$ days for the duration time and between 700 and $890^{\circ} \mathrm{C}$ for the temperature. The temperature experienced by B-7904 was estimated in a number of previous studies based on several lines of evidence: higher than $750^{\circ} \mathrm{C}$ from the presence of minor decomposed saponite (Akai, 1992), intermediate between $600^{\circ} \mathrm{C}$ and $700^{\circ} \mathrm{C}$ based on the labile trace element patterns (Paul and Lipschutz, 1989), and below $600^{\circ} \mathrm{C}$ based on the presence of the hydrous-anhydrous intermediate phases (Zolensky et al., 1991). The temperatures estimated by Akai (1992) and Paul and Lipschutz (1989) are consistent with our estimate, but that by Zolensky et al. (1991) is lower than ours. Zolensky et al. (1991) conducted a heating experiment of Murchison at temperatures from 400 to $800^{\circ} \mathrm{C}$ for 1 week $(168 \mathrm{~h})$ under reduced conditions. They found discrete crystals of secondary olivine and pyroxene in the products heated at $700^{\circ} \mathrm{C}$ or higher and the hydrous-anhydrous intermediate phases in both B-7904 and the products heated at $600^{\circ} \mathrm{C}$ or lower. They therefore concluded that the temperature of heating for B-7904 is lower than $600^{\circ} \mathrm{C}$. Our FE-SEM observation also revealed that the matrix of $\mathrm{B}-$ 7904 contains low-crystalline phases together with crystalline secondary olivine (Fig. 5(d)), which is consistent with the observations of Zolensky et al. (1991). In our heating experiment of Murchison, we observed only wellcrystalline olivine and pyroxene in the $900^{\circ} \mathrm{C} / 96 \mathrm{~h}$ product (Fig. 5(c)), which is again consistent with the results of heating at $800^{\circ} \mathrm{C} / 168 \mathrm{~h}$ in Zolensky et al. (1991). However, the low-crystalline phases were still retained in our experimental product heated at $900^{\circ} \mathrm{C} / 1 \mathrm{~h}$, suggesting that the low-crystalline phases can survive high-temperature heating, if the duration is short. In summary, our temperature estimate agrees with that of Zolensky et al. (1991), if the heating duration is taken into consideration.

\subsection{Heat source}

There are several heat sources and mechanisms that cause the dehydration of hydrous asteroids, including thermal metamorphism in the interior of asteroids, impact-induced heating, and solar radiation heating. It is widely accepted that the decay energy extracted from the extinct nuclide of ${ }^{26} \mathrm{Al}$ is a main heat source for the thermal metamorphism of anhydrous asteroids (McSween et al., 1988). In the case 
of hydrous asteroids, however, the main heating mechanism is still unknown. As pointed out in Grimm and McSween (1989), it seems difficult to increase the temperature of the hydrous asteroids as a whole due to the large latent heat and the heat capacity of water as well as the enhanced heat loss by hydrothermal convection. However, a hydrous asteroid with a radius of more than $20 \mathrm{~km}$ can be heated to 500 $700^{\circ} \mathrm{C}$ if the $\mathrm{Al}$ content of the asteroid is similar to that of the CI- and CM-chondrites and the initial ${ }^{26} \mathrm{Al} /{ }^{27} \mathrm{Al}$ ratio is $5 \times 10^{-6}$ (Miyamoto, 1991). The high temperature induced by the internal heating is long lasting - on the order of $10^{6}-$ $10^{8}$ years-because the asteroid is heated almost entirely except for surface layers (Miyamoto et al., 1981). Conversely, the time of heating experienced by B-7904 is much shorter (10-10 $0^{3}$ days) compared with the timescale of the internal heating. Even if the parent asteroid was broken into pieces during its high-temperature regime, the time of heating cannot be shortened significantly because it takes time on the order of $10^{6}$ year or longer to raise the temperature of the asteroid higher than $600^{\circ} \mathrm{C}$ (Miyamoto et al., 1981). Therefore, we suggest here that the ${ }^{26} \mathrm{Al}$ decay energy is not responsible for the heating of B-7904.

There are several mechanisms that cause the short-lasting heating of asteroids, including impacts and solar radiation, but it is difficult to identify any one mechanism based only on the time and the temperature of heating. Shock heating is proposed for the short-duration temperature elevation of B-7904 based on the survival of the unequilibrated mineral assemblages, such as schreibersite-phosphate (Kimura and Ikeda, 1992). Shock experiments on Murchison in a range of pressures from 10.0 to $39.6 \mathrm{GPa}$ were performed to reproduce phyllosilicate decomposition in B-7904 (Akai and Sekine, 1994). These researchers found that the equilibrium shock pressure of $32 \mathrm{GPa}$ is needed for the decomposition of phyllosilicates. At this pressure, partial melting of fine-grained matrix occurs in Murchison (Tomeoka et al., 1999; Tomioka et al., 2007). In our study, partially melted troilite-taenite objects were found on the chondrule surfaces (Fig. 3), which indicates that the temperature exceeded $988^{\circ} \mathrm{C}$ in limited portions in B-7904. The heterogeneous temperature distribution during heating is consistent with impact-induced heating, because shock temperatures vary between places depending on the porosity and the shock impedance of the impacted material (e.g., Dijken and De Hosson, 1994; Schmitt et al., 1994). On the other hand, solar-radiation heating increases the temperature of the surface of asteroids, possibly resulting in phyllosilicate decomposition if the perihelion of the asteroid is close to 0.1 AU, such as the F-type asteroid Phaethon (e.g., Ohtsuka et al., 2006). In this case, the heat transfer is limited to the surface layers of asteroids due to low heat conductivity. The lack of implanted solar-wind noble gases in B-7904 (Nakamura et al., 2006) may contradict the solar-radiation heating mechanism. In addition, many time circulations on the orbit close to the sun could have similar effects to a long-duration heating. Therefore, if the orbit of the parent asteroid of B7904 is as stable as that of Phaethon (Ohtsuka et al., 2006), the solar radiation may not be the possible heat source for the dehydration of B-7904.

\section{Conclusions}

In order to constrain the thermal history of the B-7904 $\mathrm{CM}$ carbonaceous chondrite, heating experiments of the Murchison $\mathrm{CM}$ chondrite were carried out at $600^{\circ} \mathrm{C} / 1 \mathrm{~h}$, $600^{\circ} \mathrm{C} / 96 \mathrm{~h}, 900^{\circ} \mathrm{C} / 1 \mathrm{~h}$, and $900^{\circ} \mathrm{C} / 96 \mathrm{~h}$ under controlled oxygen partial pressures. The mineralogical and the chemical properties of B-7904 are well reproduced in the products heated at $900^{\circ} \mathrm{C} / 1 \mathrm{~h}$ and $900^{\circ} \mathrm{C} / 96 \mathrm{~h}$. Based on both the experimental results and the occurrence of temperaturesensitive minerals, the ranges of temperature and time for the heating of B-7904 are estimated to be from 10 to $10^{3}$ days at $700^{\circ} \mathrm{C}$ and from 1 to $10^{2} \mathrm{~h}$ at $890^{\circ} \mathrm{C}$. The obtained time duration is apparently shorter than the time required for the internal heating by the decay of a short-lived radiogenic nuclide, ${ }^{26} \mathrm{Al}$. The most probable heat source is impact-induced heating, although solar-radiation heating cannot be ruled out.

Acknowledgments. The authors wish to thank Drs. M. Kimura and T. Hiroi for the review, Dr. T. Nakamoto for handling of the manuscript, Dr. K. Ohtsuka for discussion, Drs. H. Nagahara, S. Tachibana, and H. Yoshida for technical support during the FE-SEM observation, Dr. Y. Yamamoto, Messrs. Y. Kakazu, S. Nishida, and N. Ohashi, Mses. K. Jogo and K. Sakamoto for technical support during the X-ray diffraction analysis at the High Energy Accelerator Research Organization, Messrs. N. Ohashi and S. Nishida for technical support during the micro-Raman spectroscopy at the Ibaraki University, and Mr. K. Shimada for help with the EPMA analysis. This work has been supported by the Grant-in-aid of the Japan Ministry of Education, Culture, Sports, Science and Technology to TN (No. 17340157).

\section{References}

Akai, J., Incompletely transformed serpentine-type phyllosilicates in the matrix of Antarctic CM chondrites, Geochim. Cosmochim. Acta, 52, 1593-1599, 1988.

Akai, J., Mineralogical evidence of heating events in carbonaceous chondrites, Y-86720 and Y-82162, Proc. NIPR Symp. Antarctic Meteor., 3, 55-68, 1990.

Akai, J., TTT-diagram of serpentine and saponite, and estimation of metamorphic heating degree of Antarctic carbonaceous chondrite, Proc. NIPR Symp. Antarctic Meteor., 5, 120-135, 1992.

Akai, J. and T. Sekine, Shock effects experiments on serpentine and thermal metamorphic conditions in Antarctic carbonaceous chondrite, Proc. NIPR Symp. Antarctic Meteor., 7, 101-109, 1994.

Beyssac, O., B. Goffé, C. Chopin, and J. N. Rouzaud, Raman spectra of carbonaceous material in metasediments: a new geothermometer, $J$. Metamorphic Geol., 20, 859-871, 2002.

Bischoff, A. and K. Metzler, Mineralogy and petrography of the anomalous carbonaceous chondrites, Yamato-86720, Yamato-82162 and Belgica7904, Proc. NIPR Symp. Antarctic Meteor., 4, 226-246, 1991.

Cuesta, A., P. Dhamelincourt, J. Laureyns, A. Martinez-Alonso, and J. M. D. Tascon, Raman microprobe studies on carbon materials, Carbon, 32, 1523-1532, 1994.

Deer, W. A., R. A. Howie, and J. Zussman, An Introduction to the RockForming Minerals second edition, Longman Scientific and Technical, Essex, 627, 1992.

Dijiken, D. K. and J. Th. M. De Hosson, Thermodynemic model of compaction of powder materials by shock waves, J. Appl. Phys., 75, 203209, 1994.

Etschmann, B., A. Pring, A. Putnis, B. A. Grgyric, and A. Studer, A kinetic study of the exsolution of pentlandite $(\mathrm{Ni}, \mathrm{Fe})_{9} \mathrm{~S}_{8}$ from the monosulfide solidsolution (Fe,Ni)S, Am. Mineral., 89, 39-50, 2004.

Fuchs, L. H., E. Olsen, and K. J. Jensen, Mineralogy, mineral chemistry, and compositions of the Murchison (C2) meteorite, Smithsonian Contr. Earth Sci., 10, 1-39, 1973.

Gaffey, M. J., J. F. Bell, and D. P. Cruikshank, Reflectance spectroscopy and asteroid surface mineralogy, in Asteroid II, edited by R. P. Binzel, T. Gehrels, and M. S. Matthews, 98-127, Univ. Arizona Press, Tucson, Arizona, 1989. 
Grimm, R. E. and H. Y. McSween, Water and thermal evolution of carbonaeous chondrite parent bodies, Icarus, 82, 244-280, 1989.

Hiroi, T. and M. E. Zolensky, UV-VIS-NIR absorption features of heated phyllosilicates as remote-sensing clues of thermal histories of primitive asteroids, Antarctic Meteor. Res., 12, 108-116, 1999.

Hiroi, T., C. Peters, M. E. Zolensky, and P. Lipschutz, Evidence of thermal metamorphism of C, G, B, and F asteroid, Science, 261, 1016-1018, 1993.

Hiroi, T., C. Peters, M. E. Zolensky, and P. Lipschutz, Possible thermal metamorphism of the $\mathrm{C}, \mathrm{G}, \mathrm{B}$, and $\mathrm{F}$ asteroids detected from their reflectance spectra in comparison with carbonaceous chondrites, Proc. NIPR Symp. Antarctic Meteor., 7, 230-243, 1994.

Hiroi, T., C. Peters, M. E. Zolensky, and P. Lipschutz, Thermal metamorphism of the $\mathrm{C}, \mathrm{G}, \mathrm{B}$ and $\mathrm{F}$ asteroids seen from the $0.7 \mu \mathrm{m}, 0.3 \mu \mathrm{m}$, and UV absorption strengths in comparison with carbonaceous chondrites, Meteor. Planet. Sci., 31, 321-327, 1996.

Ikeda, Y., Petrology and mineralogy of the Yamato-82162 chondrite (CI), Proc. NIPR Symp. Antarctic Meteor., 4, 187-225, 1991.

Ikeda, Y., An overview of the research consortium, "Antarctic carbonaceous chondrites with CI affinities, Yamato-86720, Yamato-82162 and Belgica-7904", Proc. NIPR Symp. Antarctic Meteor., 5, 49-72, 1992.

Jarosewich, E., Chemical analyses of meteorites: A compilation of stony and iron meteorite analyses, Meteoritics, 25, 323-337, 1990.

Jawhari, T., A. Roid, and J. Casado, Raman-spectroscopic characterization of some commercially available carbon-black materials, Carbon, 33, 1561-1565, 1995.

Katagiri, G., H. Ishida, and A. Ishitani, Raman-spectra of graphite edge planes, Carbon, 26, 565-571, 1988.

Kimura, M. and Y. Ikeda, Mineralogy and petrology of an unusual Belgica7904 carbonaceous chondrites: genetic relationships among the components, Proc. NIPR Symp. Antarctic Meteor., 5, 74-119, 1992.

Kitajima, F., T. Nakamura, N. Takaoka, and T. Murae, Evaluating the thermal metamorphism of CM chondrites by using pyrolytic behavior of the carbonaceous macromolecular matter, Geochim. Cosmochim. Acta, 66, 163-172, 2002.

MacKinnon, I. D. R. and M. E. Zolensky, Proposed structures for poorly characterized phases in $\mathrm{C} 2 \mathrm{M}$ carbonaceous chondrite meteorites, $\mathrm{Na}$ ture, 309, 240-242, 1984.

MacSween, H. Y., D. W. G. Sears, and R. T. Dodd, Thermal metamorphism, in Meteorites and the Early Solar System, edited by J. F. Kerridge and M. S. Matthews, 102-113, Univ. Arizona Press, Tucson, Arizona, 1988.

Metzler, K., A. Bischoff, and D. Stöffler, Accretionary dust mantles in CM chondrite: Evidence for solar nebula processes, Geochim. Cosmochim. Acta, 56, 2873-2897, 1992.

Misener, D. J., Cationic diffusion in olivine to $1400^{\circ} \mathrm{C}$ and $35 \mathrm{kbar}$, in Geochemical Transport and Kinetics, edited by A. W. Hofmann et al., 117-129, Carnegie Inst. Washington, 1974.

Miyamoto, M., Thermal metamorphism of CI and CM carbonaceous chondrites: An internal heating model, Meteoritics, 26, 111-115, 1991.

Miyamoto, M., N. Fujii, and H. Takeda, Ordinary chondrite parent body: An internal heating model, Proc. Lunar Planet Sci., 12B, 1145-1152, 1981.

Nagao, K., K. Inoue, and K. Ogata, Primordial rare gases in Belgica-7904 (C2) Carbonaceous Chondrite, Mem. NIPR Spec. Issue, 35, 257-266, 1984.

Nakamura, T., Post-hydration thermal metamorphism of carbonaceous chondrites, J. Mineral. Petrol. Sci., 100, 260-272, 2005.

Nakamura, T. and Y. Nakamuta, X-ray study of PCP from the Murchison CM carbonaceous chondrites, Proc. NIPR Symp. Antarctic Meteor., 9, 37-50, 1996.
Nakamura, T., R. Okazaki, and G. R. Huss, Thermal metamorphism of $\mathrm{CM}$ carbonaceous chondrite: effects on phyllosilicate mineralogy and presolar grain abundances, Lunar Planet. Sci. Conf., 37th, 1633pdf, 2006.

Nakamura, T., A. Tsuchiyama, T. Akaki, K. Uesugi, T. Nakano, A. Takeuchi, Y. Suzuki, and T. Noguchi, Bulk mineralogy and three dimensional structures of individual Stardust particles deduced from synchrotron X-ray diffraction and microtomography analysis, Meteor. Planet. Sci., 43, 247-259, 2008.

Ohtsuka, K., T. Sekiguchi, D. Kinoshita, J.-I. Watanabe, Y. Ito, H. Arakida, and T. Kasuga, Apollo asteroid 2005 UD: split nucleus of (3200) Phaethon?, Astron. Astrophys., 450, L25-L28, 2006.

Paul, R. L. and M. E. Lipschutz, Labile trace elements in some Antarctic carbonaceous chondrite: Antarctic and Non-Antarctic meteorite comparisons, Z. Naturf., A44, 979-987, 1989.

Schmitt, R. T., A. Deutsch, and D. Stöffler, Calculation of hugoniot curves and post-shock temperatures for $\mathrm{H}$ - and L-chondrites, Lunar Planet. Sci. Conf., 25, 1209pdf, 1994.

Tomeoka, K., Mineralogy and petrology of Belgica-7904: A new kind of carbonaceous chondrite from Antarctica, Proc. NIPR Symp. Antarctic Meteor., 3, 40-54, 1990a.

Tomeoka, K., Phyllosilicate vein in a CI meteorite: evidence for aqueous alteration on the parent body, Nature, 345, 138-140, 1990b.

Tomeoka, K. and P. R. Buseck, A new layered mineral from the Mighei CM2 carbonaceous chondrite, Nature, 306, 354-356, 1983.

Tomeoka, K. and P. R. Buseck, Indicators of aqueous alteration in CM carbonaceous chondrites: Microtextures of a layered mineral containing Fe, S, O and Ni, Geochim. Cosmochim. Acta, 49, 2143-2163, 1985.

Tomeoka, K., H. Kojima, and K. Yanai, Yamato-86720: A CM carbonaceous chondrite having experienced extensive aqueous alteration and thermal metamorphism, Proc. NIPR Symp. Antarctic Meteor., 2, 55-74, 1989a.

Tomeoka, K., H. Kojima, and K. Yanai, Yamato-82162: a new kind of CI carbonaceous chondrite from Antarctica, Proc. NIPR Symp. Antarctic Meteor., 2, 36-54, 1989b.

Tomeoka, K., Y. Yamahara, and T. Sekine, Experimental shock metamorphism of the Murchison CM carbonaceous chondrite, Geochim. Cosmochim. Acta, 63, 3683-3703, 1999.

Tomioka, N., K. Tomeoka, K. Nakamura-Messenger, and T. Sekine, Heating effects of the matrix of experimentally shocked Murchison CM chondrite: Comparison with micrometerites, Meteor. Planet. Sci., 42, 19-30, 2007.

Tuinstra, F. and J. L. Koenig, Raman spectrum of graphite, J. Chem. Phys., 53, 1126-1130, 1970 .

Wang, A., P. Dhamelincourt, J. Dubessy, D. Guerard, P. Landais, and M. Lelaurain, Characterization of graphite alteration in an uranium deposit by micro-Raman spectroscopy, X-ray-diffraction, transmission electron-microscopy and scanning electron-microscopy, Carbon, 27, 209-218, 1989.

Yabuta, H., H. Naraoka, K. Sakanishi, and H. Kawashima, Solid-state ${ }^{13} \mathrm{C}$ NMR characterization of insoluble organic matter from Antarctic CM2 chondrites: Evaluation of the meteoritic alteration level, Meteor. Planet. Sci., 40, 779-787, 2005.

Zolensky, M. E., M. Prinz, and M. E. Lipschutz, Mineralogy and thermal history of Y-82162, Y-86720 and B-7904, Papers Presented to the 16th Symposium on Antarctic Meteorites, June 5-7, Tokyo, Natl Inst. Polar Res., 195-196, 1991.

A. Nakato (e-mail: aiko@geo.kyushu-u.ac.jp), T. Nakamura, F. Kitajima, and T. Noguchi 